\title{
Unpacking Configurational Dynamics: Sequence Analysis and Qualitative Comparative Analysis as a Mixed-Method Design
}

\author{
Camilla Borgna and Emanuela Struffolino
}

\section{Introduction}

Sequence analysis (SA) was introduced in the social sciences in the 1980s: Andrew Abbott, inspired by the treatment of DNA strings in biology, developed it as a technique to study social processes that unfold over time as sequences of events (Abbott and Forrest 1986). In contrast to the variable-oriented approach of techniques like event-history analysis, which focus on the timing of specific transitions, SA's approach is holistic and case-oriented (Billari 2005). This implies looking at the whole picture of individuals' longitudinal realizations rather than at the effects of variables on single-event outcomes. Against this scenario, processes of change over the life course are regarded as successions of states/actions located within constraining or enabling structures. This reflects (Abbott 1992)'s idea that holistic and analytical approaches can be combined into a multicase narrative methodology, based on which researchers can compare the unfolding of processes to pursue categorization and generalization.

SA has been extensively applied in demography and life-course research to study changes and continuities in individual pathways over time (e.g. Aassve et al. 2007;

The original version of this chapter was revised. A correction to this chapter is available at https:// doi.org/10.1007/978-3-319-95420-2_17

C. Borgna $(\square)$

Collegio Carlo Alberto, Turin, Italy

e-mail: camilla.borgna@ carloalberto.org

E. Struffolino $(\square)$

WZB Berlin Social Science Center - Research Group 'Demography and Inequality' and Humboldt University of Berlin, Berlin, Germany

e-mail: emanuela.struffolino@wzb.eu 
Brzinsky-Fay and Solga 2016; Fasang and Raab 2014; Raitano and Struffolino 2013). Other fields of application include social policy analysis (Frank et al. 2000), democratization research (Wilson 2014), electoral participation studies (Buton et al. 2014), historical sociology (Abbott and Forrest 1986; Mercklé and Zalc 2014), and developmental psychology (Dietrich et al. 2014). The mainstream application of SA relies on optimal matching techniques to measure the distance between sequences that represent the individual realization of a certain process and on the clustering of such sequences to identify typical trajectories. Regression analysis is often applied as a second step to investigate why (and not only how) sequences resemble or differ from each other (Aisenbrey and Fasang 2010). Yet, multivariate regression analysis, with its focus on the net effects of single variables, seems to be at odds with the case-oriented nature of SA. In this chapter, we propose to use qualitative comparative analysis (QCA) as a second, explanatory step for SA. Compared to regression analysis, QCA is more coherent with SA's epistemological framework, because it shares the notion of analytically approaching social phenomena without disregarding their complexity. QCA was introduced in the 1980s (Ragin 1987) and relies on methodological tools that were uncommon in social science until then: in this case, logic and in particular Boolean and fuzzy-set algebra. Its developer Charles Ragin, like Abbott, aimed at bridging the divide between variable-oriented and case-oriented research. However, the joint holistic and analytical perspective of QCA does not concern over-time trajectories, but rather configurations of factors at given time points.

We contribute to the growing literature on mixed-methods research (e.g. Creswell 2009; Teddlie and Tashakkori 2006) by putting forward a novel "sequential mixedmethod design" (Hollstein 2014; Teddlie and Tashakkori 2006) that consists of applying a recent innovation in SA-the so-called discrepancy analysis of state sequences (Studer et al. 2011; Struffolino et al. 2016) — as a first step, and crisp-set (Ragin 1987) or fuzzy-set (Ragin 2000, 2008) QCA as a second step. Our proposed framework allows researchers to analyze individual trajectories as a whole and to identify combinations of factors that are systematically linked to variations in the unfolding of such trajectories at potentially critical turning points. This can be read as an answer to the call for a "processual sociology" (Abbott 2016) that can take on the challenge of investigating both the dynamics of social phenomena as lineages of successive events and the complexity of contextual characteristics of "present" moments.

\section{Sequence Analysis and Qualitative Comparative as a Sequential Mixed-Methods Design}

Qualitative comparative analysis (QCA) is a method that permits systematic comparisons of cases through the highly-formalized tools of logic and set theory. Its perspective on the study of social phenomena is inherently analytical, but at the same time holistic and case-oriented (Berg-Schlosser et al. 2009; Ragin 1987; Schneider and Wagemann 2012). 
In the QCA framework, cases are understood as complex entities of interrelated attributes. Empirically, this means that cases are classified as members or nonmembers of multiple and possibly overlapping sets. For instance, when investigating countries as cases, researchers can label them as "democracies" but also as "industrial economies," "corporatist welfare states" and so on. Each of these labels represents a set to which the country case can either belong or not. Similarly, if cases are represented by individuals rather than countries, researchers could envisage sets such as "working population," "women," "mothers," etc. While belonging to one set always implies not belonging to its negation, different sets are not mutually exclusive, as all mothers are women (subset relation) and some women are part of the working population (set intersection), for instance. In its original formulationlater known as crisp-set QCA—set membership was dichotomous, while the later development of fuzzy-set QCA (Ragin 2000, 2008) permits a more fine-grained assessment: Set membership can vary in a continuum from 0 to 1 (as, for instance, individuals who work few hours a week could be considered as partial members of the set "working population").

QCA can be used as a classification tool, for example for typology building (Berg-Schlosser et al. 2009). However, most of the applications so far have taken an explanatory perspective in assessing the empirical regularities that exist between some factors and an outcome (Marx et al. 2014). Typical fields of application include comparative politics (Schneider 2009), welfare studies (Emmenegger 2011; Vis 2009), policy and administration (Sager and Thomann 2016), sociology of work and education (Borgna 2016; Glaesser and Cooper 2010), and organization research (Fiss 2011). The technique consists of a first step dedicated to identifying (combinations of) conditions in presence of which the cases systematically display a given outcome (a procedure known as truth-table construction). In a second step, redundant elements are removed from these configurations by applying Boolean or fuzzy-set algebra (i.e. truth-table minimization). The resulting Boolean expression represents the logically-minimal combinations of factors that are sufficient for the occurrence of the outcome and are sometimes defined as "outcome-enabling context" (Schneider and Wagemann 2012).

In a nutshell, QCA is a powerful method for systematically comparing cases without ruling out their potentially configurational nature. This complements the approach of SA, which underlines the complexity of cases in terms of sequencing of states and duration of events.

In this contribution, we bring together the strengths of SA and QCA in a sequential mixed-methods design. We propose applying SA in a first research stage, in order to describe both qualitatively and quantitatively the temporal complexity of a given social process. By applying QCA in a second stage, it is possible to shed light on the configurational complexity at given phases along the process and to reduce such complexity to synthetic combinations of explanatory factors. This combination is not a simple juxtaposition of methods but rather a genuine example of crossfertilization between two methodological traditions that arose from the same desire to "bring cases back" in quantitative analysis (Ragin and Becker 1992). By adopting our proposed research design, researchers can approach complexity from different 
angles and thus explore its temporal and configurational dimensions within the same analytical framework. This exploration is a first step towards the identification of what (Abbott 1992, 2009) has called "turning points" along the unfolding of social processes.

Practically, the steps of our proposed framework are the following: (1) sequence construction, where each time point is designated as a categorical state identifying the outcome of interest; (2) discrepancy analysis of state sequences, where we identify the phases when a given factor is mostly or increasingly relevant to explain inter-sequence differences; (3) truth-table construction, where we assess for each of these phases which combinations of factors are systematically associated with the outcome; (4) truth-table analysis, where the logically-sufficient factors for the occurrence of the outcome are identified.

\section{Empirical Illustration}

To illustrate the added value of our approach, we apply it to the study of women's employment trajectories in divided Germany (1955-1990). The leading research question for this exercise is: what conditions enabled women in East and West Germany to continue their education or employment over early- and mid-adulthood? This question is suitable for our illustrative purposes because there is extensive literature that accounts for the factors shaping women's labor-market participation within the two contexts (Diewald et al. 2006; Rosenfeld et al. 2004). This enables us to evaluate our results against a wide range of established, substantive evidence.

\subsection{Background}

During the period of division (1955-1990), the German Democratic Republic (henceforth, East Germany) and the Federal Republic of Germany (henceforth, West Germany) differed to a great extent concerning their economic and welfare systems.

The social market economy in West Germany was coupled with the promotion of a pro-traditional male breadwinner model in a corporative welfare state (Engelhardt et al. 2002; Rosenfeld et al. 2004). A highly gendered division of labor was indirectly supported by social policies that did not promote the compatibility of work and family and by a taxation system that penalized working wives (Brückner 2004; Cooke 2011; Sainsbury 1999). Female labor-market participation was around $50 \%$ - mostly part-time - and it was discouraged especially for women with children, while for male employment rates were around 80\% (Diewald et al. 2006).

In the egalitarian centrally planned economy of East Germany, women's employment was supported by an infrastructure and an ideology that affirmed the right and duty to work. Pro-natalist family policies aimed at improving compatibility of work and family: The normative pressure to have children in one's early twenties was 
combined with widespread childcare, and state-controlled resources (e.g. housing or loans) were available to those who started a family (Kreyenfeld 2004). As a result, women's employment rates paralleled men's, reaching $90 \%$ also for women with children (Huinink et al. 1995).

When considering enabling conditions for employment, we expect gender to play a major role in the explanation of inter-individual differences along the whole life course, and especially so when specific life transitions occurred. Moreover, given the institutional differences outlined above, we expect gender to be a prominent explanatory factor in the West more than in the East. Finally, within each context, we expect some combinations of factors to be consequential for women's employment. We focus on three drivers that the literature indicates to be relevant to female labor participation (Engelhardt et al. 2002; Kreyenfeld 2004; Rosenfeld et al. 2004): partnership status, number of children, and parental education.

To develop our empirical illustration, we analyze longitudinal-retrospective data from the Starting Cohort Six of the National Educational Panel Study (NEPS) (Blossfeld et al. 2011). We selected a subsample of individuals born in East and West Germany ( $N=374$ and $N=1,695$ respectively) between 1944 and 1955, i.e. individuals who experienced most of their early- and mid-adulthood in divided Germany.

\subsection{Empirical Analysis}

In a first step, we construct individual sequences representing longitudinal employment trajectories of men and women in West and East Germany. We then apply discrepancy analysis of state sequences to estimate the proportion of the variation in employment trajectories explained by gender at each time point in the sequences. This allows us to identify the phases when gender is mostly or increasingly relevant.

In a second step, we focus on these time points and apply fuzzy-set QCA to the sample of women to identify the configurations of factors sufficient for them to be employed or pursuing education in West and East Germany.

\subsubsection{Step 1: Sequence Analysis}

\section{Sequences' Construction}

We construct individual employment trajectories from ages 15 to 40 as sequences of monthly intervals ${ }^{1}$ : each of the 300 months is encoded according to a binary definition that distinguishes being in education or employment from being out of education and out of employment (unemployment, inactivity, military service, maternity leave). We adopt this binary definition because both crisp- and fuzzyset QCA require a two-dimensional outcome. This does not rule out the possibility

\footnotetext{
${ }^{1}$ All analyses are performed in R.3.2.5 by using the packages TraMineR, TraMineRextras (Gabadinho et al. 2011), and WeightedCluster (Studer 2013). For a discussion on the choice of the distance measure see Studer and Ritschard (2016).
} 

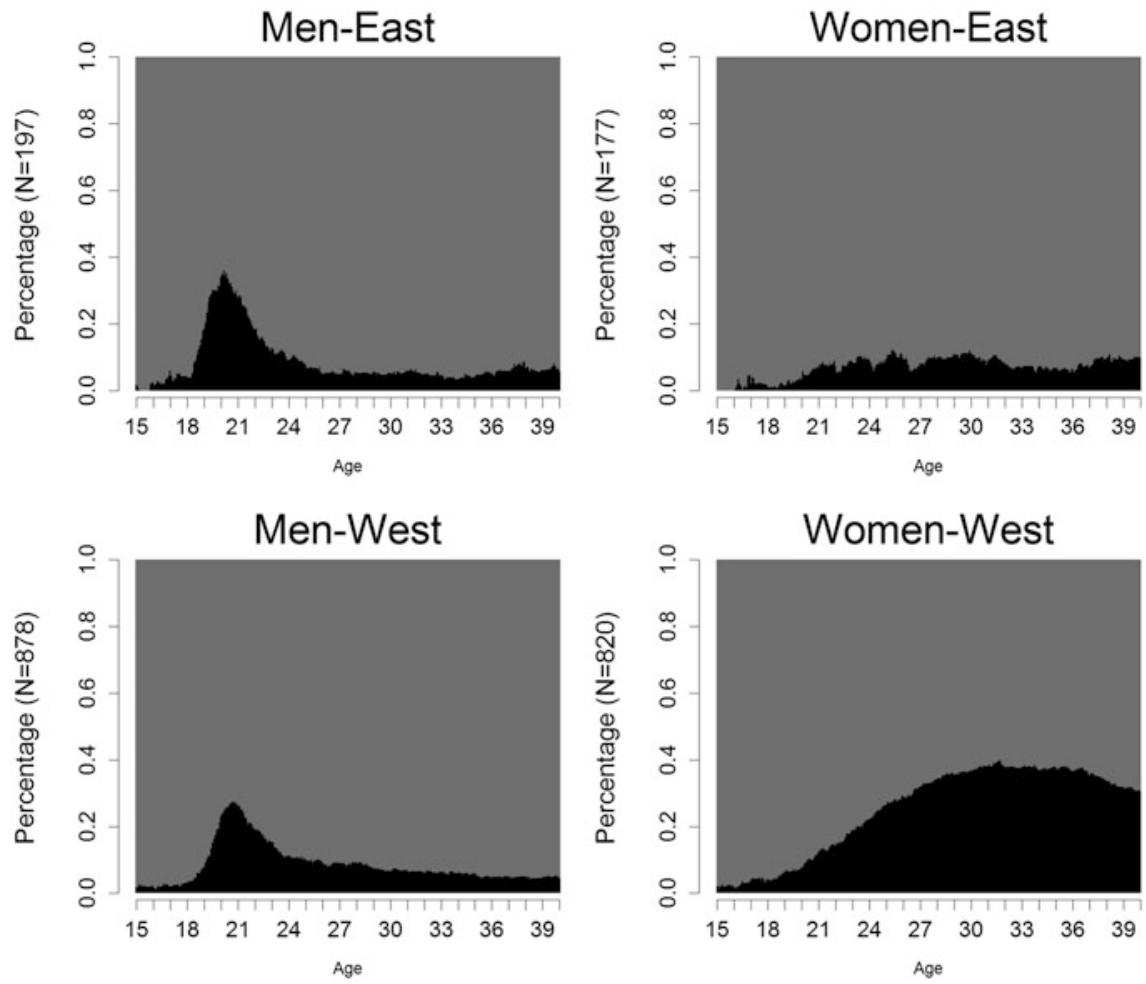

Out of employment/not in education

Employed/in education

Fig. 1 State distribution plot by gender and context: Percentage of individuals in a certain state at each point in time. (Source: authors' elaboration on NEPS data)

of adopting more elaborate definitions of states, as SA could be combined with multi-value QCA (Cronqvist and Berg-Schlosser 2009). From a substantive point of view, being in employment or in education is often considered a "positive" outcome during early adulthood and one that is associated with greater chances of societal integration later on. We censor our observational window at age 40 because we assume that the most important steps for the establishment of one's career have already occurred during this phase of the life course.

Figure 1 shows the state distribution plot by gender in East and West Germany. For men, periods spent out of employment or education were concentrated in the years around military service in both contexts. In contrast, women's employment trajectories differed according to context: while women in the East exhibited very limited amounts of time spent out of employment over the whole timespan considered, in West Germany women's likelihood of being in employment or education decreases over time. 


\section{Discrepancy Analysis}

We apply discrepancy analysis of state sequences (DA) (Studer et al. 2011), which translates the ANOVA framework into sequence analysis. The resulting pseudo- $R^{2}$ values can be interpreted as the share of the total variability between sequences explained by a specific factor of interest at each point in time (for a detailed description see Struffolino et al. 2016). The input of DA is a pairwise distance matrix based on a dissimilarity measure computed by assigning a cost to each transformation needed to align the couples of sequences (insertion-deletion and substitution costs). We used the optimal matching dissimilarity measure with an insertion-deletion cost of 1 and a substitution cost of 2. Notice that in this case, the sequences are composed of only two states, and therefore any more complex specification of costs would have been pointless (Studer and Ritschard 2016). Our explanatory factor of interest is gender. Hence, the pseudo- $R^{2}$ value for betweengroup differences at each time point can be interpreted as the share of the total variability in the pool of sequences that is explained by gender.

Figure 2 displays the pseudo- $R^{2}$ values for gender in East and West Germany. In the East, gender explains $12 \%$ of the variation between employment trajectories around age 20: this is most probably due to men being in military service. After age 23, gender explains very little of the variation between trajectories, because employment rates were very high for both men and women. In contrast to this, in the West gender explains an increasing share of the variability between employment trajectories starting from age 22; it reaches $15 \%$ between age 30 and 36 .

The peaks in the pseudo- $R^{2}$ represent phases of the life course where gender differences reach their relative maximum: These phases are of particular substantive interest because they might represent 'turning points' along the unfolding of employment trajectories (Abbott 2009). However, within the SA framework, change is understood as lasting over a period of time, rather than as happening at specific time points (Shanahan 2000). Divergence between sequences may then result from an extended succession of critical moments and not necessarily concentrate at single peaks. Therefore, both the peaks and the phases where gender differences display sharp increase can be considered as potential turning points. We randomly select one specific time point (month) for phases of peaks and sharp increases. To be able to compare between the two contexts, we additionally selected time points in the West and applied them to the East, and vice versa. This results in five time points that constitute the starting point for our second step of analysis: 19 years, 20 years and 9 months, 23 years, 31 years, and 35 years.

\subsubsection{Step 2: Qualitative Comparative Analysis}

In the second research stage, we shift the focus to women, because it is their patterns that diverge from those of men, at least in the West, and investigate which configurations of factors are systematically associated with being in employment or in education at each of the five time points identified in the first research stage and within the two contexts of East and West Germany. Our explanatory conditions refer 


\section{East}

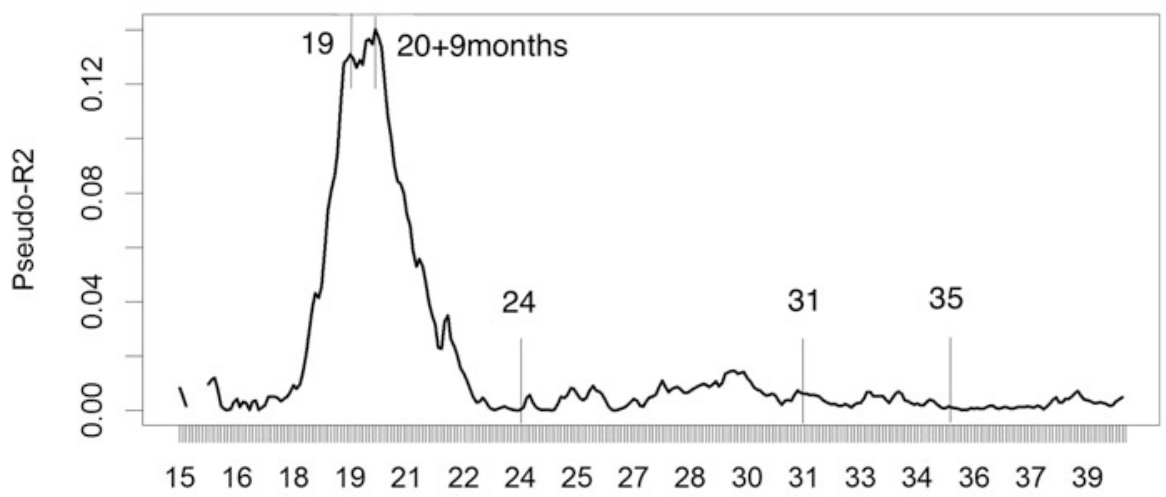

Age

\section{West}

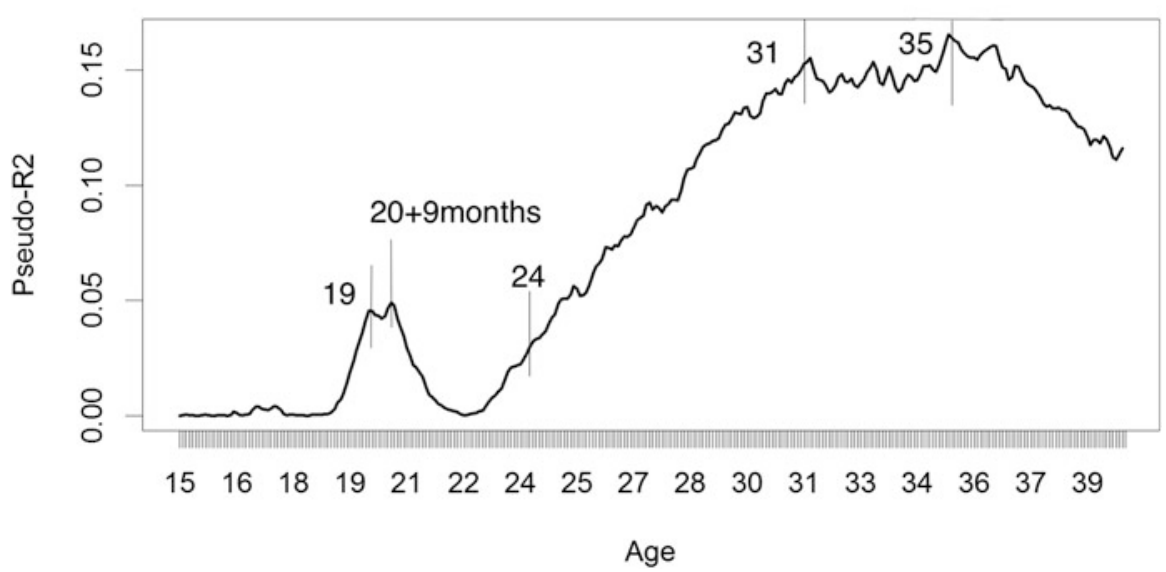

Fig. 2 Share of the variability in employment trajectories over time explained by gender in East and West Germany: Pseudo- $R^{2}$ values. (Source: authors' elaboration on NEPS data)

to women's partnership status, number of children, and family background. While many other factors could be listed as potentially explanatory, for the sake of simplicity of this empirical exercise we focus on the three identified as the most relevant according to previous literature (see Sect.3.1). Moreover, parsimony in identifying potentially explanatory conditions is required when applying QCA, as the number of possible combinations grows exponentially with the inclusion of new conditions.

\section{Calibration}

As mentioned in Sect.2, to apply QCA, the cases under observation must be classified as members or non-members of the sets corresponding to the outcome 
and the explanatory conditions. While in principle researchers can attribute set membership based on their own substantive knowledge of the cases, set membership is often assigned following the more systematic procedure of calibration, which consists of applying external criteria to transform an interval-scale variable into a crisp or fuzzy set. ${ }^{2}$

Two calibration techniques can be distinguished: Following the direct method (Ragin 2008, 94-97), researchers need to specify three values of the interval scale (also known as "source variable") that will identify three qualitative breakpoints in the set membership: full inclusion, full exclusion, and maximum ambiguity or crossover. For fuzzy sets, full inclusion usually corresponds to a set membership of 0.99 , full exclusion to 0.01 , and the crossover to 0.5 , while intermediate values are assigned according to a logistic function. For crisp sets, only the value corresponding to the crossover must be specified, as set membership can only assume the value of 0 or 1 . Instead, when following the indirect method of calibration, one should use substantive knowledge to determine the correspondence between values of the source variable and set membership scores. The recommended set membership scores are: 1 for full inclusion, 0.8 for cases "mostly but not fully in the target set," 0.6 for cases "more in than out of the target set," 0.4 for cases "more out than in of the target set," 0.2 for cases "mostly but not fully out of the target set," and 0 for full exclusion (Ragin 2008, 95-96). For both the direct and indirect calibration methods, the threshold criteria need to be justifiable and transparent. In our empirical application, cases are constituted by individuals — or more specifically, women-in East and West Germany observed at each of the five time points selected in the SA analytical step. The criteria for the calibration of the sets corresponding to the outcome and to the explanatory conditions are detailed in the following.

Outcome: Crisp set of "women in employment or in education". In this case no calibration is necessary because the source variable, corresponding to the two states analyzed in the first research stage, is already dichotomous (see above).

\section{Explanatory Conditions:}

- PARTNERSHIP: fuzzy set of "women in a stable partnership"; source variable: self-reported marital status; method of calibration: indirect; threshold criteria and set memberships: single: 0; cohabiting but unmarried: 0.6; married: 1 .

- CHILDREN: crisp set of "women with children"; source variable: number of children; method of calibration: direct; threshold criteria and set memberships: no children: 0 for one or more children: 1 .

- HIGH-PAREDU: fuzzy set of "women from relatively advantaged social background"3; source variable: number of years corresponding to the highest educational qualification attained by either parent; method of calibration: direct; threshold criteria and set memberships: these are specific to the two contexts

\footnotetext{
${ }^{2}$ Remember that for crisp sets membership is dichotomous, while for fuzzy sets it can vary in a continuum between 0 and 1 .

${ }^{3}$ For the sake of simplicity, in what follows we shall talk of "highly educated parents" vs. "nonhighly educated parents". However, cases belonging to this set should be understood as women originating from households where at least one parent has at least an intermediate level of education - hence, a proxy for a relatively advantaged social background.
} 
Table 1 Descriptive statistics for the outcome and the conditions, by context and time point

\begin{tabular}{|c|c|c|c|c|c|c|c|c|c|c|}
\hline \multirow[b]{2}{*}{ Variable } & \multicolumn{5}{|c|}{ Age, EAST Germany } & \multicolumn{5}{|c|}{ Age, WEST Germany } \\
\hline & 19 & $20+9 m$ & 24 & 31 & 35 & 19 & $20+9 \mathrm{~m}$ & 24 & 31 & 35 \\
\hline \multicolumn{11}{|l|}{ Employment status } \\
\hline $\begin{array}{l}\text { Out of employment/ } \\
\text { not in education }\end{array}$ & 1.5 & 6.6 & 9.4 & 9.4 & 6.8 & 6.3 & 10.6 & 22.3 & 39.8 & 37.7 \\
\hline $\begin{array}{l}\text { Employed/in } \\
\text { education }\end{array}$ & 98.5 & 93.4 & 90.6 & 90.6 & 93.2 & 93.7 & 89.4 & 77.7 & 60.2 & 62.3 \\
\hline \multicolumn{11}{|l|}{ Partnership status } \\
\hline Single & 90.9 & 55.5 & 17.1 & 7.5 & 8 & 87.3 & 63.3 & 25.8 & 7.4 & 8.7 \\
\hline Cohabiting & 2.4 & 9.2 & 6.4 & 4.2 & 4.6 & 2.1 & 6.5 & 10 & 8.5 & 5.4 \\
\hline Married & 6.8 & 35.4 & 76.5 & 88.3 & 87.4 & 10.6 & 30.2 & 64.3 & 84.1 & 85.9 \\
\hline \multicolumn{11}{|l|}{ Number of children } \\
\hline 0 & 93.2 & 70.2 & 26 & 6.9 & 3.8 & 92.9 & 82.5 & 61.5 & 23.2 & 18.7 \\
\hline 1 & 6.3 & 29 & 57.8 & 34.1 & 33.1 & 6.6 & 15.2 & 27.6 & 30.9 & 28 \\
\hline 2 & 0.5 & 0.3 & 15.4 & 49.4 & 51.4 & 0.6 & 2.1 & 9.7 & 37.1 & 40.2 \\
\hline 3 & 0 & 0.5 & 0.3 & 8.5 & 10.4 & 0 & 0.3 & 1.2 & 6.6 & 9.4 \\
\hline $4+$ & 0 & 0 & 0.5 & 1.1 & 1.4 & 0 & 0 & 0.1 & 2.2 & 3.7 \\
\hline \multicolumn{11}{|c|}{ Parental education (years) } \\
\hline 8 & 0.2 & & & & & 0.8 & & & & \\
\hline 9 & 1.8 & & & & & 9.8 & & & & \\
\hline 10 & 0 & & & & & 0.3 & & & & \\
\hline 12 & 73.7 & & & & & 64.8 & & & & \\
\hline 13 & 6.6 & & & & & 11.8 & & & & \\
\hline 15 & 3.6 & & & & & 4.8 & & & & \\
\hline 16 & 2.7 & & & & & 1.7 & & & & \\
\hline 18 & 11.3 & & & & & 6.2 & & & & \\
\hline $\mathrm{N}$ & 177 & 177 & 177 & 177 & 177 & 820 & 820 & 820 & 820 & 820 \\
\hline
\end{tabular}

Source: authors' elaboration on NEPS data $m$ months

to account for the differences in the degrees of educational expansion and in the educational systems. East Germany: 15.5 years (university education): $0.99 ; 12.5$ years (above the 12 threshold corresponding to upper-secondary education): 0.5 ; 11 years (less than upper-secondary education): 0.01. West Germany: 15.5 years (university education): $0.99 ; 11$ years (above the 10 threshold corresponding to the intermediate school certificate): $0.5 ; 9.5$ (no or low school certificate only): 0.01 .

Table 1 reports descriptive information on the source variables for the outcome and the conditions for each time point and context. 
Table 2 Truth tables for the presence of the outcome, by context and time points

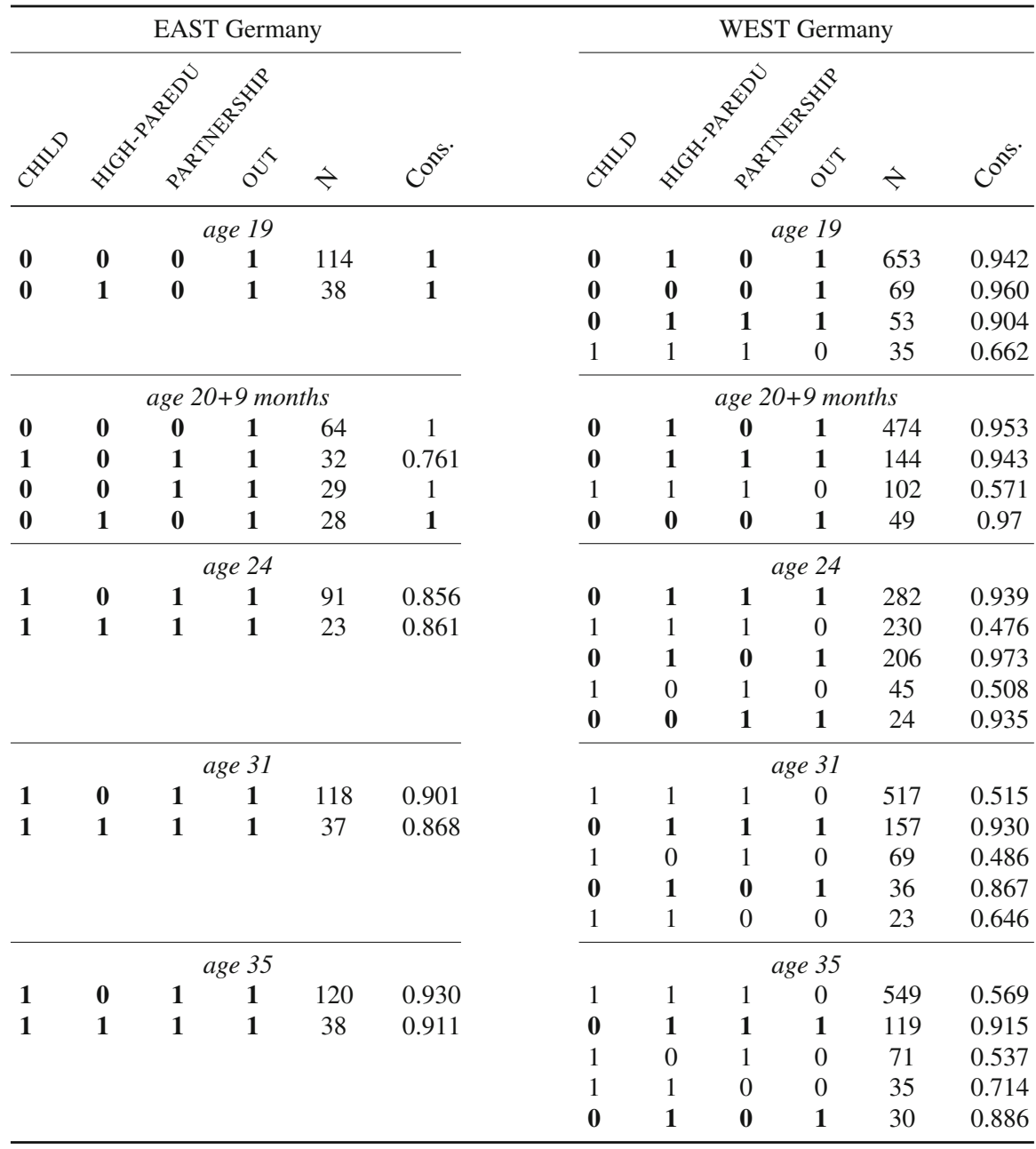

Source: authors' elaboration on NEPS data. Logical remainders $(\mathrm{N}<20)$ omitted for parsimony. Consistency threshold: 0.75. In bold: configurations associated with the presence of the outcome.

\section{Truth-Table Construction}

Before proceeding to the analysis, we explore the empirical configurations displayed by the cases and their relation with the outcome for each time point and context. To this scope, we construct a so-called "truth table," whose rows correspond to possible combinations of conditions. Based on the empirical distribution of cases, each combination is connected to either the presence or the absence of the outcome. The 10 resulting truth tables are displayed in Table 2. 
The intersection of our three conditions (CHILDREN, HIGH-PAREDU, PARTNERSHIP) produces eight possible configurations. However, not all configurations display empirical instances and some rows are therefore empty (the so-called "logical remainders"). To minimize random noise, we set a frequency threshold of 20 cases, meaning that configurations with less than 20 cases are classified as logical remainders. ${ }^{4}$ In Table 2, logical remainders are omitted for parsimony. Each row represents a combination of conditions (with 1 indicating the presence, and 0 the absence of the condition) to which a certain number of cases $(\mathrm{N})$ belongs. For instance, the first row in the right part of the table indicates that, in the sample of West Germany, when they were 19 years old, 635 women did not have any children, came from highly educated families, and were not in a partnership (CHILDREN $=0$, HIGH-PAREDU $=1$, PARTNERSHIP $=0$ ). Among them, the vast majority was in employment or in education (OUT $=1)$, as indicated by the consistency parameter (Cons. $=0.942)$. This parameter, roughly speaking, returns the proportion of women belonging to the 0-1-0 configuration who were in employment or in education. ${ }^{5}$

Table 2 reveals that in each of the five time points, for both the East and the West, multiple configurations were associated with the outcome. In East Germany, this applies to all existing configurations (i.e. displaying at least 20 empirical instances), in line with the fact that in this context the great majority of women remained in employment (or education) throughout their whole life course (see Fig. 1).

Looking more closely at Table 2, we note that, with the exception of the second time point, there are only two configurations for East Germany. Moreover, they are constant for the last three time points: women in stable partnerships and with children, with (1-1-1) and without (1-0-1) highly educated parents. This finding is consistent with previous research underlining the standardization of individual life courses in the GDR (Fasang and Raab 2014; Struffolino et al. 2016). More diversity existed in West Germany. This is visible first of all in the number of rows that exhibit empirical instances: Women are generally grouped in four or five configurations. Second, such configurations vary considerably over time, as can be seen from the comparison of the rows across time points. Finally, some configurations are associated with the presence and some with the absence of the outcome.

\section{Truth-Table Analysis}

In order to remove the redundant elements from the configurations associated with the outcome and thus identify the "outcome-enabling" conditions, we perform the fuzzy-set minimization of the 10 truth tables. ${ }^{6}$ Different strategies exist in the literature for dealing with the issue of limited diversity, which emerges in QCA as non-existent configurations or logical remainders (Schneider and Wagemann 2012, 160-177). Given the descriptive purpose of our analysis, we refrain from

\footnotetext{
${ }^{4}$ Alternatively, one could set a relative threshold corresponding to a given share of cases, e.g. $5 \%$.

${ }^{5}$ More precisely, the consistency parameter indicates the extent to which the fuzzy set corresponding to the 0-1-0 configuration is a subset of the fuzzy set corresponding to the outcome.

${ }^{6}$ The analyses were performed using the QCA package (Thiem and Duşa 2013) in R.3.2.5 using the Enhanced Quine-McCluskey Algorithm without row dominance rule.
} 
using logical remainders, meaning that configurations with less than 20 cases are not considered in the minimization process. Therefore, our solutions are to be intended as conservative (ivi: 182). Additionally, before proceeding to the analysis one must set a consistency threshold in order to exclude configurations that are not sufficient subsets of the outcome. We apply a consistency threshold of 0.75 , which is generally considered acceptable in the QCA literature (ibidem), but results are generally robust even with stricter consistency levels. ${ }^{7}$

The results are summarized in Table 3, whose columns represent the five time points and whose rows display the "prime implicants." The prime implicants are the essential components of a configuration identified by the truth-table analysis that, read in combination with each other, constitute the logically-minimal Boolean expression sufficient for the presence of the outcome (Ragin 1987, 95-98). For example, for 19-year-old West-German women, in order to be in employment or in education, it was sufficient not to have children and not to be in a partnership, or, as an alternative, not to have children and to have highly educated parents. The resulting logically-minimal Boolean expression is therefore: "child*partnership + child*HIGH-PAREDU". ${ }^{8}$

Table 3 thus shows the dynamic development of the combinations of factors logically sufficient for being in employment or in education. Indeed, these combinations changed over time during the phases of early- and mid-adulthood in both contexts. In both East and West Germany, not having children and not being in a partnership emerges a prime implicant for the first two time points considered, although in combination with different prime implicants (high-paredu*PARTNERSHIP in the East and child*HIGH-PAREDU in the West), but later disappears. As women reached the stage of their life course when most entered partnerships and had children, the

Table 3 Prime implicants for the presence of the outcome, by context and time point

\begin{tabular}{l|l|l|l|l|l|l|l|l|l|l|l}
\hline & \multicolumn{3}{l}{ Age, EAST Germany } & \multicolumn{5}{l}{ Age, WEST Germany } \\
\cline { 2 - 13 } Prime implicant & 19 & $20+9 \mathrm{~m}$ & 24 & 31 & 35 & 19 & $20+9 \mathrm{~m}$ & 24 & 31 & 35 \\
\hline CHILDREN*PARTNERSHIP & & & $\bullet$ & $\bullet$ & $\bullet$ & & & & & \\
\hline high-paredu*PARTNERSHIP & & $\bullet$ & & & & & & & & \\
\hline children*high-paredu & & & & & & & & & & \\
\hline children*PARTNERSHIP & & & & & & & & $\bullet$ & & \\
\hline children*partnership & $\bullet$ & $\bullet$ & & & & $\bullet$ & $\bullet$ & & & \\
\hline children*HIGH-PAREDU & & & & & & $\bullet$ & $\bullet$ & $\bullet$ & $\bullet$ & $\bullet$ \\
\hline
\end{tabular}

Source: authors' elaboration on NEPS data. Conservative solutions. Consistency threshold: 0.75 . Upper-case letters represent the presence and lower-case letters the absence of the condition $m=$ months

\footnotetext{
${ }^{7}$ Applying consistency thresholds between 0.76 and 0.85 produces results identical to those displayed in Table 3, with the exception of the second prime implicant, which in this case consists of "child*high-paredu*PARTNERSHIP."

${ }^{8}$ In Boolean language, upper-case letters represent the presence and lower-case letters the absence of the condition; the star sign represents the logical AND (set intersection) and the plus sign represents the logical OR (set union).
} 
combinations of factors sufficient for remaining in employment or in education diverged across the two contexts: In East Germany, the only prime implicant from 24 years on is constituted by women in a partnership and with children. In West Germany, where the transition to fertility was generally delayed compared to the East (Kreyenfeld 2004), for 24-year-old women we still find the alternative combinations of not having children and having highly educated parents or or not having children and being in a partnership. However, from age 31, the only prime implicant left is that of women without children and with highly educated parents.

For both contexts, we observe a collapse over time into a single prime implicant. However, the implications are very different for East and West Germany: The prime implicant for East Germany (being in a partnership and with children) corresponds to the prevailing configuration of attributes for women aged 24 and older. Moreover, for these Eastern German women, the outcome is skewed to the right or, in other words, the overwhelming majority were in employment or in education (consistently with what shown by Huinink et al. 1995). Hence, the prime implicant and the outcome are in a relation of almost perfect set coincidence, which should not be interpreted as causal but rather as constitutive (Borgna 2013). In substantive terms, as noted earlier, this is driven by a strong standardization of individual life courses (Fasang and Raab 2014; Struffolino et al. 2016). In West Germany, in contrast, the lasting prime implicant corresponds to a limited portion of the population and can therefore properly be read as "outcome-enabling": Among women older than 24, only those without children and with highly educated parents could systematically still be found in employment or in education. The prime implicant of women in a partnership and without children disappears, because for ages 31 and 35 it corresponds to a group that is too small to be considered an existing configuration, because the great majority of women in a partnership eventually had children, and those who did not have any originate from families with highly educated parents (see also Table 2).

Overall, while we detected a greater heterogeneity in the life courses of women in West Germany from the mere observation of the truth tables, the truth-table analyses suggest that this greater diversity does not translate into a greater variety of pathways towards employment or education. While further research would be needed for any definitive, substantial conclusions, the results of this empirical exercise are not only in line with previous evidence on women's labor-market participation in East and West Germany but also provide some new insights into the different degree of complexity of their life courses.

\section{Concluding Remarks}

In this contribution, we have put forward a sequential mixed-methods design to unpack the temporal and configurational complexity of social phenomena. By applying SA, researchers can analyze the unfolding of phenomena over time in terms of sequencing of states and duration of events. More specifically, through 
discrepancy analysis of state sequences, researchers can identify the crucial points in time when trajectories (start to) diverge from each other. In a second research stage, QCA can be applied to investigate whether, at such crucial time points, some particular combinations of factors explain why the cases display a given state (or outcome). By analyzing these cross-sectional turning points sequentially, we preserve the longitudinal and holistic perspective on trajectories.

We have illustrated the usefulness of our framework with an empirical analysis of employment trajectories in divided Germany. We have shown that, especially for West Germany, gender significantly explains the divergence of trajectories at what we characterized as turning points in women's life course. Moreover, while a plurality of factors initially explain women's presence in employment or education in both contexts, only one configuration of factors for each context is systematically linked to the outcome at the end of the period considered. Hence, by combining SA and QCA, we were able to unveil the dynamic of conditions sufficient for women to be in employment or education.

Notwithstanding the specificities of our empirical illustration, we believe that our proposed framework holds the promise of being useful to a wide range of researchers from a variety of disciplinary fields and who are interested in various kinds of micro-, meso-, and macro-level processes that involve a temporal and configurational dimension. We limit ourselves to three fields for which this SAQCA design clearly appears to be valuable. First, recent developments in social stratification research have emphasized the role of cumulative advantage (DiPrete and Eirich 2006) and intersectionality (Platt 2011) but struggle to combine the two aspects in a single analytical framework. Second, a holistic perspective on both the context of implementation and the process of change is central in policy analysis and evaluation, especially for the approach of theory-based evaluation (Befani and Sager 2006). Third, the definition of "critical junctures" in the historical institutionalist tradition (Thelen 1999) appears to bear more than one similarity to our treatment of outcome-enabling configurations at turning points along the sequences. Similarly, Schneider and Rohlfing (2013) and more recently Williams and Gemperle (2017) have called for an integration of QCA and process-tracing methodologies to identify the "situational" causal mechanisms. Future research could explore the potential of combining our SA-QCA framework with more qualitative methods, like process tracing to the study of social processes and critical junctures in particular.

Acknowledgements We thank Anette E. Fasang for generously sharing the routines for data preparation and providing helpful comments and suggestions on an earlier version of this chapter. For insightful comments, we are also grateful to David Brady, Markus Siewert, Eva Thomann, as well as to the participants in the Colloquia Quantico at the ISW-Humboldt University of Berlin and CO:STA at the WZB Berlin Social Science Center. We thank Ana Santiago-Vela for excellent research assistance. 


\section{References}

Aassve, A., Billari, F. C., \& Piccarreta, R. (2007). Strings of adulthood: A sequence analysis of young British women's work-family trajectories. European Journal of Population/Revue européenne de Démographie, 23(3-4), 369-388.

Abbott, A. (1992). From causes to events: Notes on narrative positivism. Sociological Methods \& Research, 20(4), 428-455.

Abbott, A. (2009). A propos du concept de Turning Point. In M. Bessin, C. Bidart, \& M. Grossetti (Eds.), Bifurcations: les sciences sociales face aux ruptures et à l'événement (pp. 187-211). Paris: La Découverte.

Abbott, A. (2016). Processual sociology. Chicago: Chicago University Press.

Abbott, A., \& Forrest, J. (1986). Optimal matching methods for historical sequences. The Journal of Interdisciplinary History, 16(3), 471-494.

Aisenbrey, S., \& Fasang, A. E. (2010). New life for old ideas: The "second wave" of sequence analysis bringing the "course" back into the life course. Sociological Methods \& Research, 38(3), 420-462.

Befani, B., \& Sager, F. (2006). QCA as a tool for realistic evaluations the case of the swiss environmental impact assessment. In B. Rihoux \& H. Grimm (Eds.), Innovative comparative methods for policy analysis. Beyond the quantitative-qualitative divide (pp. 263-284). Boston: Springer.

Berg-Schlosser, D., De Meur, G., Rihoux, B., \& Ragin, C. (2009). Qualitative comparative analysis (QCA) as an approach. In B. Rihoux \& C. C. Ragin (Eds.), Configurational comparative methods (pp. 1-19). London: SAGE.

Billari, F. C. (2005). Life course analysis: Two (complementary) cultures? Some reflections with examples from the analysis of the transition to adulthood. Advances in Life Course Research, 10, 261-281.

Blossfeld, H.-P., Rossbach, H.-G., von Maurice, J., Schneider, T., Kiesl, S. K., Schönberger, B., Müller-Kuller, A., Rohwer, G., Rässler, S., Prenzel, M. S., \& others (2011). Education as a lifelong process. The German national educational panel study (NEPS). Berlin: Springer.

Borgna, C. (2013). Fuzzy-set coincidence analysis: the hidden asymmetries. COMPASSS Working Papers Series 72.

Borgna, C. (2016). Multiple paths to inequality. How institutional contexts shape the educational opportunities of second generation immigrants in Europe. European Societies, 18(2), 180-199.

Brückner, H. (2004). Gender inequality in the life course: Social change and stability in west Germany 1975-1995. New York: De Gruyter.

Brzinsky-Fay, C., \& Solga, H. (2016). Compressed, postponed, or disadvantaged? School-to-worktransition patterns and early occupational attainment in west Germany. Research in Social Stratification and Mobility, 46, 21-36.

Buton, F., Lemercier, C., \& Mariot, N. (2014). A contextual analysis of electoral participation sequences. In P. Blanchard, F. Bühlmann, \& J.-A. Gauthier (Eds.), Advances in sequence analysis: Theory, method, applications (pp. 191-211). Berlin: Springer.

Cooke, L. P. (2011). Gender-class equality in political economies. New York: Routledge.

Creswell, J. W. (2009). Editorial: Mapping the field of mixed methods research. Journal of Mixed Methods Research, 3(2), 95-108.

Cronqvist, L., \& Berg-Schlosser, D. (2009). Multi-value QCA (mvQCA). In B. Rihoux \& C. C. Ragin (Eds.), Configurational comparative methods (pp. 145-166). London: SAGE.

Dietrich, J., Andersson, H. A., \& Salmela-Aro, K. (2014). Developmental psychologists' perspective on pathways through school and beyond. In P. Blanchard, F. Bühlmann, \& J. A. Gauthier (Eds.), Advances in sequence analysis: Theory, method, applications (pp. 129150). Cham: Springer.

Diewald, M., Goedicke, A., \& Mayer, K. U. (2006). After the fall of the wall. Life courses in the transformation of east Germany. Stanford: Stanford University Press. 
DiPrete, T. A., \& Eirich, G. M. (2006). Cumulative advantage as a mechanism for inequality: A review of theoretical and empirical developments. Annual Review of Sociology, 32, 271-297.

Emmenegger, P. (2011). Job security regulations in western democracies: A fuzzy set analysis. European Journal of Political Research, 50(3), 336-364.

Engelhardt, H., Trappe, H., \& Dronkers, J. (2002). Differences in family policies and the intergenerational transmission of divorce: A comparison between the former east and west Germany. Demographic Research, 6, 295-324.

Fasang, A. E., \& Raab, M. (2014). Beyond transmission: Intergenerational patterns of family formation among middle-class American families. Demography, 51(5), 1703-1728.

Fiss, P. C. (2011). Building better causal theories: A fuzzy set approach to typologies in organization research. Academy of Management Journal, 54(2), 393-420.

Frank, D. J., Hironaka, A., \& Schofer, E. (2000). The nation-state and the natural environment over the twentieth century. American Sociological Review, 37, 96-116.

Gabadinho, A., Ritschard, G., Müller, N., \& Studer, M. (2011). Analyzing and visualizing state sequences in R with TraMineR. Journal of Statistical Software, 4(40), 1-37.

Glaesser, J., \& Cooper, B. (2010). Selectivity and flexibility in the German secondary school system: A configurational analysis of recent data from the German socio-economic panel. European Sociological Review, 27(5), 570-585.

Hollstein, B. (2014). Mixed methods social network research: An introduction. In S. Domínguez \& B. Hollstein (Eds.), Mixed Methods Social Networks Research Design and Applications (pp. 334). New York: Cambridge University Press.

Huinink, J., Meyer, K. U., Solga, H., Sorensen, A., \& Trappe, H. (1995). Kollektiv und Eigensinn. Lebensläufe in der DDR und danach. Berlin: Akademie-Verlag.

Kreyenfeld, M. (2004). Fertility decisions in the FRG and GDR: An analysis with data from the German fertility and family survey. Demographic Research, 3(11), 276-318.

Marx, A., Rihoux, B., \& Ragin, C. (2014). The origins, development, and application of qualitative comparative analysis: The first 25 years. European Political Science Review, 6(01), 115-142.

Mercklé, P., \& Zalc, C. (2014). Trajectories of the persecuted during the Second World War: Contribution to a microhistory of the Holocaust. In P. Blanchard, F. Bühlmann, \& J.-A. Gauthier (Eds.), Advances in sequence analysis: Theory, method, applications (pp. 171-190). Berlin: Springer.

Platt, L. (2011). Understanding inequalities: Stratification and difference. Cambridge: Polity.

Ragin, C. C. (1987). The Comparative method: Moving beyond qualitative and quantitative strategies. Berkeley: University of California Press.

Ragin, C. C. (2000). Fuzzy-set social science. Chicago: University of Chicago Press.

Ragin, C. C. (2008). Redesigning social inquiry: Fuzzy sets and beyond. Chicago: University of Chicago Press.

Ragin, C. C., \& Becker, H. S. (1992). What is a case? Exploring the foundations of social inquiry. Cambridge/London: Cambridge University Press.

Raitano, M., \& Struffolino, E. (2013). Traiettorie lavorative e salariali a inizio carriera in Italia: un'analisi longitudinale. Stato e Mercato, 3(99), 389-422.

Rosenfeld, R. A., Trappe, H., \& Gornick, J. C. (2004). Gender and work in Germany: Before and after reunification. Annual Review of Sociology, 30, 103-124.

Sager, F., \& Thomann, E. (2016). Multiple streams in member state implementation: Politics, problem construction and policy paths in Swiss asylum policy. Journal of Public Policy, 37(3), $1-28$.

Sainsbury, D. (1999). Gender, policy regimes, and politics. In D. Sainsbury (Ed.), Gender and welfare state regimes. Oxford: Oxford University Press.

Schneider, C. (2009). Consolidation of democracy: Comparing Europe and Latin America. New York: Routledge.

Schneider, C. Q., \& Rohlfing, I. (2013). Combining QCA and process tracing in set-theoretic multi-method research. Sociological Methods \& Research, 42(4), 559-597.

Schneider, C. Q., \& Wagemann, C. (2012). Set-theoretic methods for the social sciences: A guide to qualitative comparative analysis. New York: Cambridge University Press. 
Shanahan, M. J. (2000). Pathways to adulthood in changing societies: Variability and mechanisms in life course perspective. Annual Review of Sociology, 26, 667-692.

Struffolino, E., Studer, M., \& Fasang, A. E. (2016). Gender, education, and family life courses in East and West Germany: Insights from new sequence analysis techniques. Advances in Life Course Research, 29, 66-79.

Studer, M. (2013). WeightedCluster library manual: A practical guide to creating typologies of trajectories in the social sciences with R. LIVES Working Papers 24, NCCR LIVES, Switzerland.

Studer, M., \& Ritschard, G. (2016). What matters in differences between life trajectories: A comparative review of sequence dissimilarity measures. Journal of the Royal Statistical Society: Series A (Statistics in Society), 179(2), 481-511.

Studer, M., Ritschard, G., Gabadinho, A., \& Muller, N. S. (2011). Discrepancy analysis of state sequences. Sociological Methods \& Research, 40(3), 471-510.

Teddlie, C., \& Tashakkori, A. (2006). A general typology of research designs featuring mixed methods. Research in the Schools, 13(1), 12-28.

Thelen, K. (1999). Historical institutionalism in comparative politics. Annual Review of Political Science, 2(1), 369-404.

Thiem, A., \& Duşa, A. (2013). QCA: A package for qualitative comparative analysis. $R$ Journal, 5(1), 87-97.

Vis, B. (2009). Governments and unpopular social policy reform: Biting the bullet or steering clear? European Journal of Political Research, 48(1), 31-57.

Williams, T., \& Gemperle, S. M. (2017). Sequence will tell! Integrating temporality into set-theoretic multi-method research combining comparative process tracing and qualitative comparative analysis. International Journal of Social Research Methodology, 20(2), 121-135.

Wilson, M. C. (2014). Governance built step-by-step: Analysing sequences to explain democratization. In P. Blanchard, F. Bühlmann, \& J.-A. Gauthier (Eds.), Advances in sequence analysis: Theory, method, applications (pp. 213-227). Berlin: Springer.

Open Access This chapter is licensed under the terms of the Creative Commons Attribution 4.0 International License (http://creativecommons.org/licenses/by/4.0/), which permits use, sharing, adaptation, distribution and reproduction in any medium or format, as long as you give appropriate credit to the original author(s) and the source, provide a link to the Creative Commons license and indicate if changes were made.

The images or other third party material in this chapter are included in the chapter's Creative Commons license, unless indicated otherwise in a credit line to the material. If material is not included in the chapter's Creative Commons license and your intended use is not permitted by statutory regulation or exceeds the permitted use, you will need to obtain permission directly from the copyright holder.

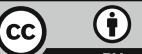

